\title{
High Fas ligand expression on lymphocytes in lesions of ulcerative colitis
}

H Ueyama, T Kiyohara, N Sawada, K Isozaki, S Kitamura, S Kondo, J Miyagawa, S Kanayama, Y Shinomura, H Ishikawa, T Ohtani, R Nezu, S Nagata, Y Matsuzawa

Second Department of Internal Medicine, Osaka University Medical School, 2-2 Yamadaoka, Suita, Osaka 565, Japan

H Ueyama T Kiyohara N Sawada

K Isozaki

S Kitamura

S Kondo

J Miyagawa

S Kanayama

Y Shinomura

Y Matsuzawa

Department of Cancer Epidemiology, Research Institute, Osaka Medical Center for Cancer and Cardiovascular Diseases, 3-3 Nakamichi 1-chome Higashinari-ku, Osaka 537, Japan S Ishikawa

T Ohtani

First Department of Surgery, Osaka University Medical School, 2-2

Yamadaoka, Suita, Osaka 565, Japan R Nezu

Department of Genetics, Osaka University Medical School, 2-2

Yamadaoka, Suita, Osaka 565, Japan S Nagata

Correspondence to: Dr H Ueyama.

Accepted for publication 4 February 1998
Abstract

Background-The pathogenesis of ulcerative colitis is unclear, but cytotoxic $\mathbf{T}$ lymphocytes infiltrating the mucosa have been implicated in mucosal damage. The Fas ligand (FasL), expressed on cytotoxic $T$ lymphocytes, induces apoptosis in cells expressing Fas.

Aim-To analyse FasL expression in affected colonic mucosa to ascertain FasFasL interaction in ulcerative colitis.

Methods-FasL mRNA was quantified in colonic mucosal specimens from healthy subjects and patients with ulcerative colitis or Crohn's disease, using the competitive reverse transcription polymerase chain reaction. FasL mRNA localisation was determined by in situ hybridisation. Expression of Fas in colonic mucosa was analysed immunohistochemically. Phenotypes of lamina propria lymphocytes that expressed FasL were analysed by flow cytometry.

Results-FasL mRNA was strongly expressed in active ulcerative colitis lesions, but not in those associated with active Crohn's disease or active proctitis-type ulcerative colitis. In situ hybridisation showed that FasL mRNA expression occurred in mononuclear cells infiltrating lesions. Fas was expressed in epithelial cells in ulcerative colitis and Crohn's disease, and in normal subjects. Cytometry showed that FasL was expressed in CD3 lymphocytes infiltrating the lamina propria in active lesions.

Conclusions-FasL is expressed in CD3 lymphocytes infiltrating into ulcerative colitis but not Crohn's disease lesions, suggesting that Fas-FasL induced apoptosis participates in the mucosal damage of ulcerative colitis.

(Gut 1998;43:48-55)

Keywords: Fas ligand; apoptosis; ulcerative colitis; reverse transcription polymerase chain reaction; $\mathrm{T}$ lymphocytes

Ulcerative colitis is characterised by chronic inflammation which is restricted to the colon mucosa. The pathogenesis of ulcerative colitis has not been determined, but a considerable body of evidence points to the involvement of autoimmune mechanisms. In clinical practice, so called autoantibodies including anti-colon antibody $^{1}$ and anti-neutrophil cytoplasmic antibody $^{2}$ are frequently detected in sera of patients with ulcerative colitis. Some of these patients also exhibit extraintestinal complications such as rheumatoid arthritis, lupus erythematosus, scleroderma, and primary sclerosing cholangitis, which may be of immunological origin. Histologically, mucosal lesions in ulcerative colitis include extensive infiltration by mononuclear cells, particularly cytotoxic T lymphocytes (CTLs), which are the putative agents for mucosal damage. Animal models include mice lacking the interleukin 2 gene $^{3}$ the interleukin 10 gene, ${ }^{4}$ or the $\mathrm{T}$ cell receptor ${ }^{5}$; such mice develop inflammatory bowel disease as well as autoimmune haemolytic anaemia. ${ }^{3}$ Collectively, the above findings are consistent with the involvement of an immune disorder in ulcerative colitis pathogenesis. Fas is a $48 \mathrm{kDa}$ type I transmembrane protein which belongs to the tumour necrosis factor/nerve growth factor receptor superfamily. ${ }^{6}$ Fas ligand (FasL) is a $40 \mathrm{kDa}$ type II transmembrane protein, which belongs to the tumour necrosis factor superfamily. ${ }^{69}$ Programmed cell death induced by the Fas-FasL system has been reported to play a physiological role in the clonal depletion of $\mathrm{T}$ lymphocytes to suppress autoimmune reactions. ${ }^{10}$ Pathologically, genetic defects of Fas and FasL in mice result in a lymphoproliferative disorder and an autoimmune disorder which resembles human lupus. ${ }^{11}{ }^{12}$ Mutations in Fas have been detected in children with a lymphoproliferative syndrome, some of whom also have a history of autoimmune disorders. ${ }^{13}{ }^{14}$ An agonistic anti-Fas antibody to Fas causes massive apoptosis of hepatocytes, suggesting a possible pathogenetic involvement in fulminant hepatitis. ${ }^{15}{ }^{16}$ FasL is expressed on the surface of CTLs, ${ }^{17}{ }^{18}$ where it functions as an effector of apoptosis in target cells that express Fas. Fas has been reported to be expressed on normal colon epithelia. ${ }^{19}$ Extensive infiltration by CTLs of colonic mucosa in ulcerative colitis suggests that FasL on CTLs may be involved in the characteristic mucosal damage. It is noteworthy that the role of FasL has not been investigated in the pathogenesis of ulcerative colitis. This paper reports an analysis of FasL mRNA expression, along with a study of its localisation in colonic lesions of patients with ulcerative colitis, using a quantitative reverse transcription polymerase chain reaction (RT-PCR) method ${ }^{20}$ and in situ hybridisation (ISH). Expression of Fas in the colonic mucosa of patients with ulcerative colitis was examined. Our results indicate that FasL mRNA is strongly expressed only in active ulcerative colitis 


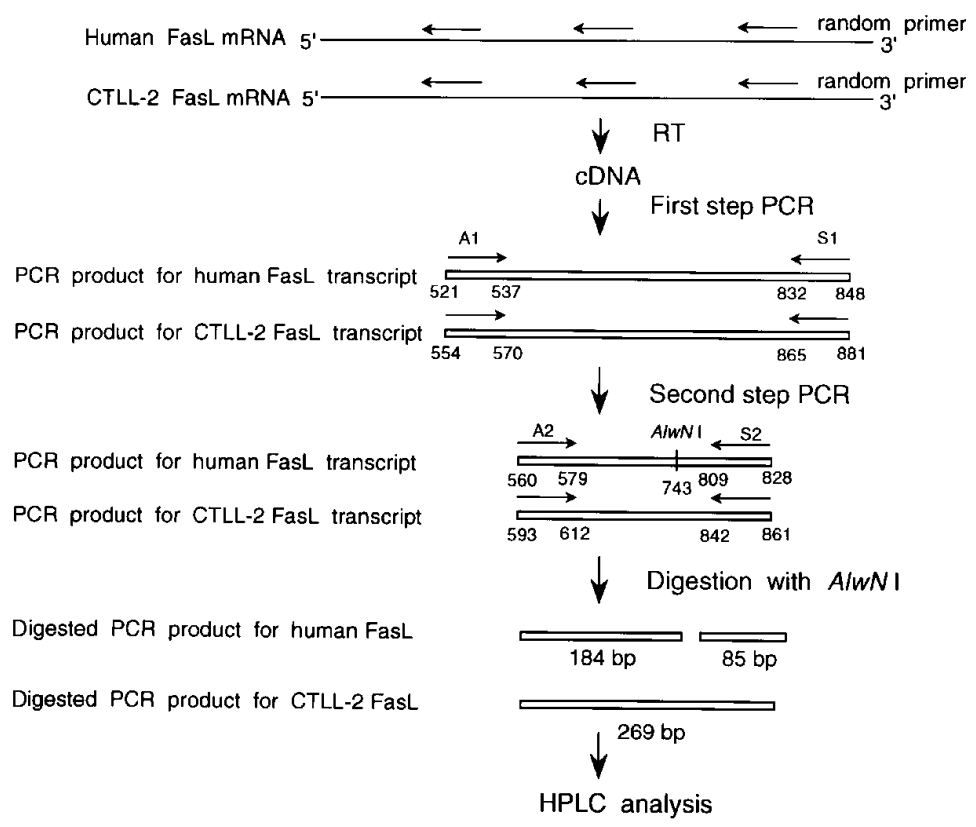

Figure 1 Protocols for the quantification of Fas ligand (FasL) transcripts. The procedures involved reverse transcription (RT), polymerase chain reaction (PCR) amplification, and digestion by AlwNI for FasL PCR products.

lesions, suggesting that the Fas-FasL system participates in the development of ulcerative colitis.

\section{Materials and methods}

MUCOSAL SPECIMENS

Biopsy specimens were obtained endoscopically from 33 sites in 23 patients with ulcerative colitis (13 men, 10 women; mean (SD) age 46.0 (11.5) years), eight patients with active Crohn's disease (three men, five women; 31.4 (9.3) years), and from nine normal colonic mucosal specimens obtained near colon polyps (controls; five men, four women; 49.6 (14.3) years). Informed consent was obtained from all the patients examined before biopsy. The patients with ulcerative colitis were classified endoscopically according to Matts' grade (grade 1 to 4 ), on the basis of the degree of inflammation of the lesions. ${ }^{22}$ Grades 1 and 2 (mild mucosal damage) were considered to be inactive and grades 3 and 4 (severe mucosal damage) to be active.

CELLS

The mouse leukaemia cell line CTLL-2, which expresses FasL, was obtained from the Riken Cell Bank (Tsukuba, Japan) and maintained in RPMI 1640 supplemented with heat inactivated fetal calf serum and antibiotics.

RATS

Female Wistar rats (6 weeks old) were purchased from Nihon Dohbutsu (Osaka, Japan) and maintained under specific pathogen free conditions.

OLIGONUCLEOTIDES USED FOR AMPLIFICATION To amplify FasL cDNA by nested PCR, we prepared the following two pairs of primers as shown in fig 1: 5'-GTGGCCCATTTAAC AGG-3' (A-1) as the first step 5' primer,

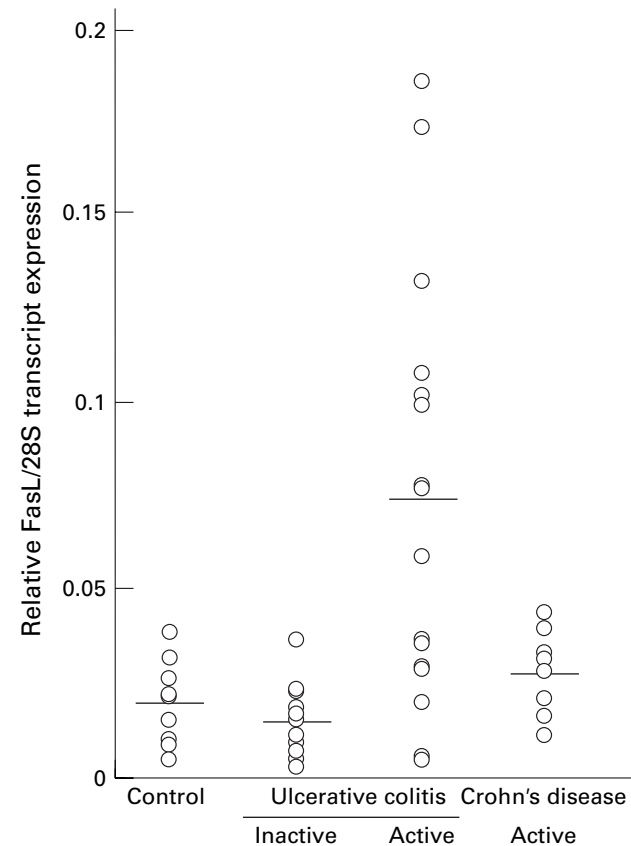

Figure 2 Amount of Fas ligand (FasL) transcript in terms of ulcerative colitis activity. Levels of FasL transcript were determined in normal colonic mucosa, colonic mucosa with active and inactive ulcerative colitis and active

Crohn's disease relative to CTLL-2 derived FasL transcript. The relative amount of Fas $L$ transcript in each colon sample was corrected on the basis of the amount of $R N A$ in the sample correlated to the amount of $28 S R N A$, determined by quantitative PCR.

5'-CAGCACTGGTAAGATTG-3' (S-1) as the first step 3' primer, 5'-CCTCTGG AATGGGAAGACAC-3' (A-2) as the second step 5' primer and 5'-ACTGCCCCCA GGTAGCTGCT-3' (S-2) as the second step 3' primer. For the amplification of $28 \mathrm{~S}$ rRNA, another pair of PCR primers was synthesised. The sequences were 5'-CCATGTGAA CAGCAGTTGAA-3' (A-3) for the 5' primer and 5'-CCCTGCCCTTCACAAAGAAA-3' (S-3) for the 3' primer. As shown in fig 1, both human and internal standard CDNAs originating from FasL mRNA are amplified by the same primers, and only the human PCR fragments of FasL had an AlwNI restriction site.

RT-PCR

Total RNAs were extracted from biopsy specimens, rat colon, and CTLL-2 cells by the acid phenol/guanidinium thiocyanate method. ${ }^{23}$ FasL transcript was quantified by a competitive RT-PCR method ${ }^{20}$ using a mixture of human colon RNA (500 ng) and CTLL-2 RNA (10 ng) or a mixture of human colon RNA (500 ng) and rat colon RNA (500 ng) for determination of the relative amounts of FasL mRNA in individual samples and for comparison of relative amounts of FasL RNA in all the samples respectively. In brief, the extracted RNAs were converted into complementary DNA (cDNA) at $37^{\circ} \mathrm{C}$ for two hours in a final volume of $25 \mathrm{ml} 10 \mathrm{mM}$ Tris/ $\mathrm{HCl}$ buffer, $\mathrm{pH}$ 8.3, containing $25 \mathrm{U}$ RAV-2 reverse transcriptase (Takara, Kyoto, Japan), 30 U RNase inhibitor (Phamacia LKB Biotechnology, Tokyo, Japan), $250 \mathrm{pmol}$ random primer 


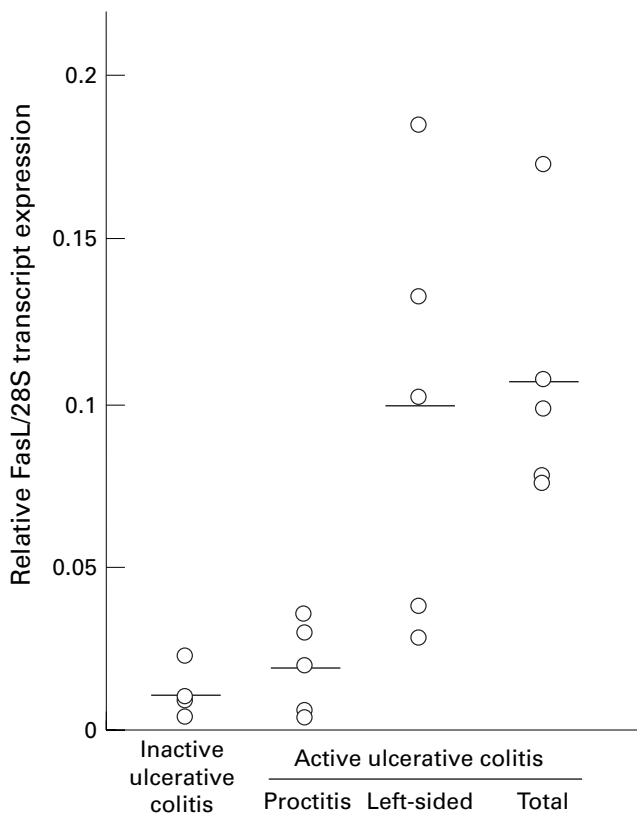

Figure 3 Relative amounts of Fas ligand (FasL) transcripts and areas involved. Relative FasL transcripts were analysed in rectal mucosal specimens of patients with active ulcerative colitis $(n=15)$ and inactive ulcerative colitis $(n=5)$, on the basis of ulcerative colitis involvement in the colon. Patients with active ulcerative colitis were divided into three subgroups: those with proctitis $(n=5)$, left sided colitis $(n=5)$, and total colitis $(n=5)$.

(Takara), $1.0 \mathrm{mM}$ dNTP (Takara), $15 \mathrm{mM}$ $\mathrm{KCl}, 2 \mathrm{mM}$ dithiothreitol, $0.6 \mathrm{mM} \mathrm{MgCl}_{2}$, and the RNA mixture. FasL cDNA was amplified in PCR buffer containing $10 \mathrm{mM}$ Tris $/ \mathrm{HCl}$, $\mathrm{pH} 8.3,50 \mathrm{mM} \mathrm{KCl}, 1.5 \mathrm{mM} \mathrm{MgCl}_{2}$, $0.0001 \%$ gelatin, $400 \mu \mathrm{M}$ each deoxynucleoside triphosphate (dNTP), $1 \mathrm{mM}$ each first step A-1 and S-1 primers, and 0.25 unit DNA Taq polymerase (Perkin-Elmer Cetus, Norwalk, Connecticut, USA). Each amplification profile involved denaturation at $94^{\circ} \mathrm{C}$ for one minute, primer annealing at $55^{\circ} \mathrm{C}$ for two minutes, and extension at $72^{\circ} \mathrm{C}$ for three minutes, which was repeated for 30 cycles. Each first step PCR product $(0.5 \mu \mathrm{l})$ was amplified in the second step PCR medium containing 1 $\mathrm{mM}$ each of the second step A-2 and S-2 primers. After the second step PCR, each sample was combined with $40 \mu \mathrm{l}$ fresh PCR medium containing second step primers, and subjected to one additional cycle to prevent heterodimeric DNA formation between the human and CTLL-2 PCR products. For the determination of $28 \mathrm{~S}$ rRNA, rat total RNA was used as the internal standard, and a cDNA mixture, converted from human and rat $28 \mathrm{~S}$ rRNA, was amplified for 30 cycles and one additional cycle with A-3 and S-3 primers as previously described. ${ }^{2021}$

QUANTIFICATION OF PCR PRODUCTS

The amount of FasL PCR product in each sample was determined relative to the PCR product of CTLL-2 derived FasL amplified in the same sample. For comparison of FasL products in all the samples examined, the relative amounts of FasL transcript were normalised to the RNA contents of the biopsy

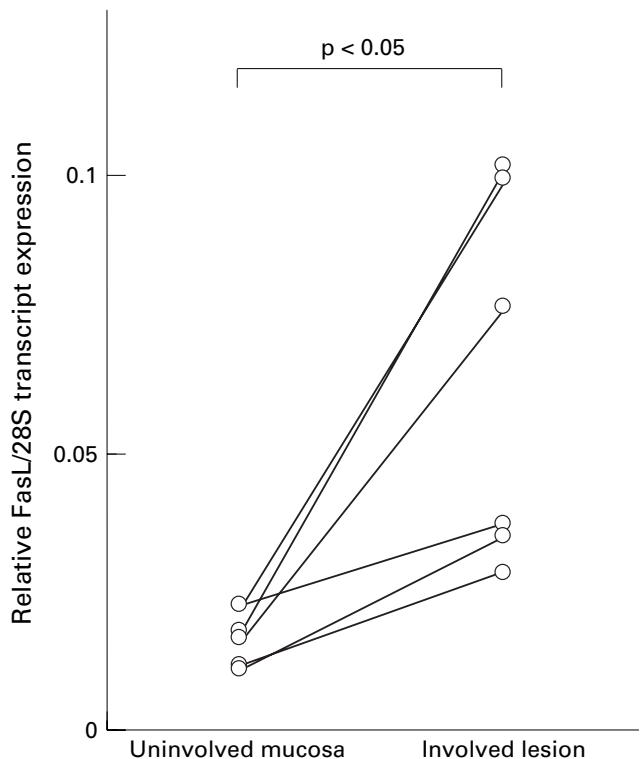

Figure 4 A comparison of Fas ligand (FasL) transcripts between uninvolved mucosa and involved lesions in the same patients in six active ulcerative colitis lesions. Involved lesions showed a significant increase in FasL transcripts in all cases ( $p<0.05$, $v$ uninvolved).

specimens, since the RNA content varies among specimens. The amount of PCR product for $28 \mathrm{~S}$ rRNA has been reported to correlate well with the total RNA content in the samples. ${ }^{20}{ }^{21}$ Thus we normalised the relative FasL PCR transcripts to $28 \mathrm{~S}$ rRNA PCR products for evaluation of FasL transcript level in the biopsy specimens. We defined the normalised FasL PCR product as the relative FasL transcript content in this study. After termination of the amplification steps, PCR products originating from FasL mRNA were digested with AlwNI (New England Biolabs, Beverly, Massachusetts, USA). As shown in fig 1, digestion of human derived PCR products for FasL gave two fragments (184 and $85 \mathrm{bp}$ ), while those derived from CTLL-2 cells for FasL (269 bp) were not digested by AlwNI. To isolate human derived products from the CTLL-2 derived products, the mixture of the two samples was separated by a high performance liquid chromatography (HPLC) system, as previously described. ${ }^{20}{ }^{21}$ PCR products were detected at $260 \mathrm{~nm}$ using a UV spectrophotometric detector, and the HPLC profile showed three separate PCR products. FasL transcript in each colon specimen was determined as the peak height of the $184 \mathrm{bp}$ fragment after normalisation to the height of the CTLL-2 FasL PCR fragment (269 bp) in the same sample. PCR for $28 \mathrm{~S}$ rRNA was performed as described previously. ${ }^{2021}$ For evaluation, the FasL transcript was corrected to the amount of 28S RNA in the same specimen, reflecting the total RNA content in the sample.

PREPARATION OF RNA PROBES AND ISH

To prepare RNA probes for FasL, a $1.0 \mathrm{~kb}$ fragment of human FasL cDNA ${ }^{24}$ was subcloned into Bluescript II pSK+ plasmid (Stratagene, La Jolla, California, USA). This 

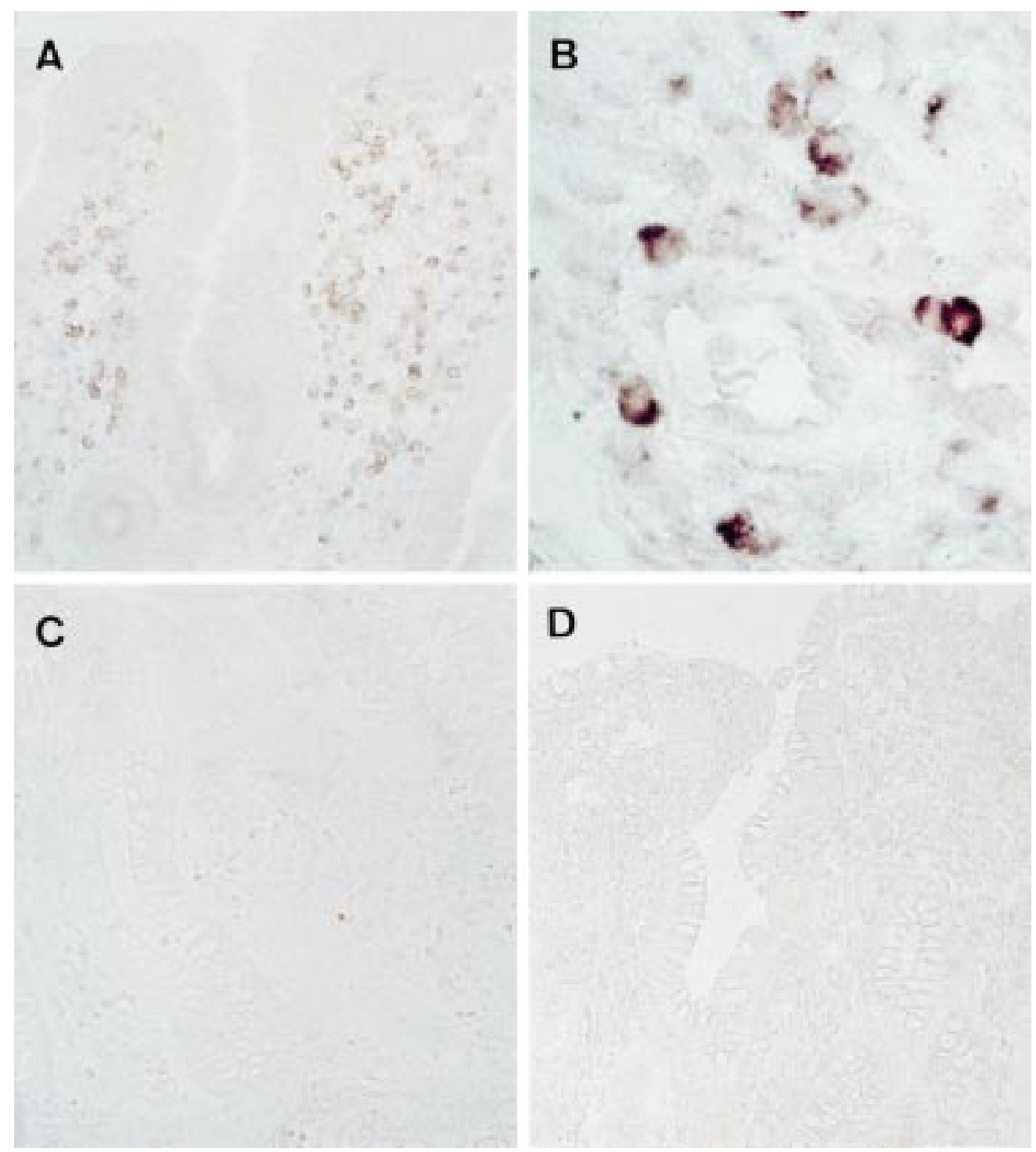

Figure 5 Expression and localisation of Fas ligand (FasL) $m R N A$ in colon specimens, as detected by in situ hybridisation (ISH). ISH was performed with an FasL antisense RNA probe in sections from an active ulcerative colitis lesion $(A, B)$, normal colonic mucosa $(C)$, and an active Crohn's disease lesion (D). Representative data are shown. The results were similar in four subjects in each group. Original magnification: $A, C$ and $D, \times 143 ; B, \times 715$

plasmid was either linearised with NotI and transcribed with T7 RNA polymerase to generate an antisense probe or linearised with EcoRV and transcribed with T3 RNA polymerase to generate a sense probe. Digoxigenin labelled single strand RNA probes were prepared by using a DIG RNA labelling kit (Boehringer Mannheim Biochemica, Mannheim, Germany), according to the manufacturer's recommended protocol. Hybridisation was carried out as previously described..$^{25}$ Briefly, surgically obtained human colonic mucosal specimens were fixed overnight with $4 \%$ paraformaldehyde in $0.1 \mathrm{M}$ phosphate buffer ( $\mathrm{pH}$ 7.2) and embedded in paraffin. Then $3 \mu \mathrm{m}$ thick sections were cut from each tissue block. Hybridisation of FasL was performed at $50^{\circ} \mathrm{C}$ for 16 hours, and the signals were detected using a nucleic acid detection kit (Boehringer Mannheim Biochemica).

\section{IMMUNOHISTOCHEMISTRY}

For immunohiostochemical analysis of Fas expression, colon tissue specimens from surgical operations were immediately frozen in liquid nitrogen. Frozen tissues were sectioned at $6 \mu \mathrm{m}$ thickness, fixed with acetone, and treated with the Dako biotin blocking system (Dako, Carpinteria, California, USA) to block endogenous avidin binding activity. After a wash in phosphate buffered saline (PBS), sections were pretreated with horse serum, followed by treatment with monoclonal mouse anti-human Fas antibody (4B4-B3) prepared by $S$ Nagata (unpublished data) at a final concentration of $5.5 \mu \mathrm{g} / \mathrm{ml}$ dissolved in PBS and $1 \%$ bovine serum albumin for 16 hours at $4^{\circ} \mathrm{C}$. The sections were washed in PBS, treated with biotinylated horse anti-mouse immunoglobulins, and stained with fluorescein avidin D (Vector Laboratories Inc., Burlingame, California, USA). 

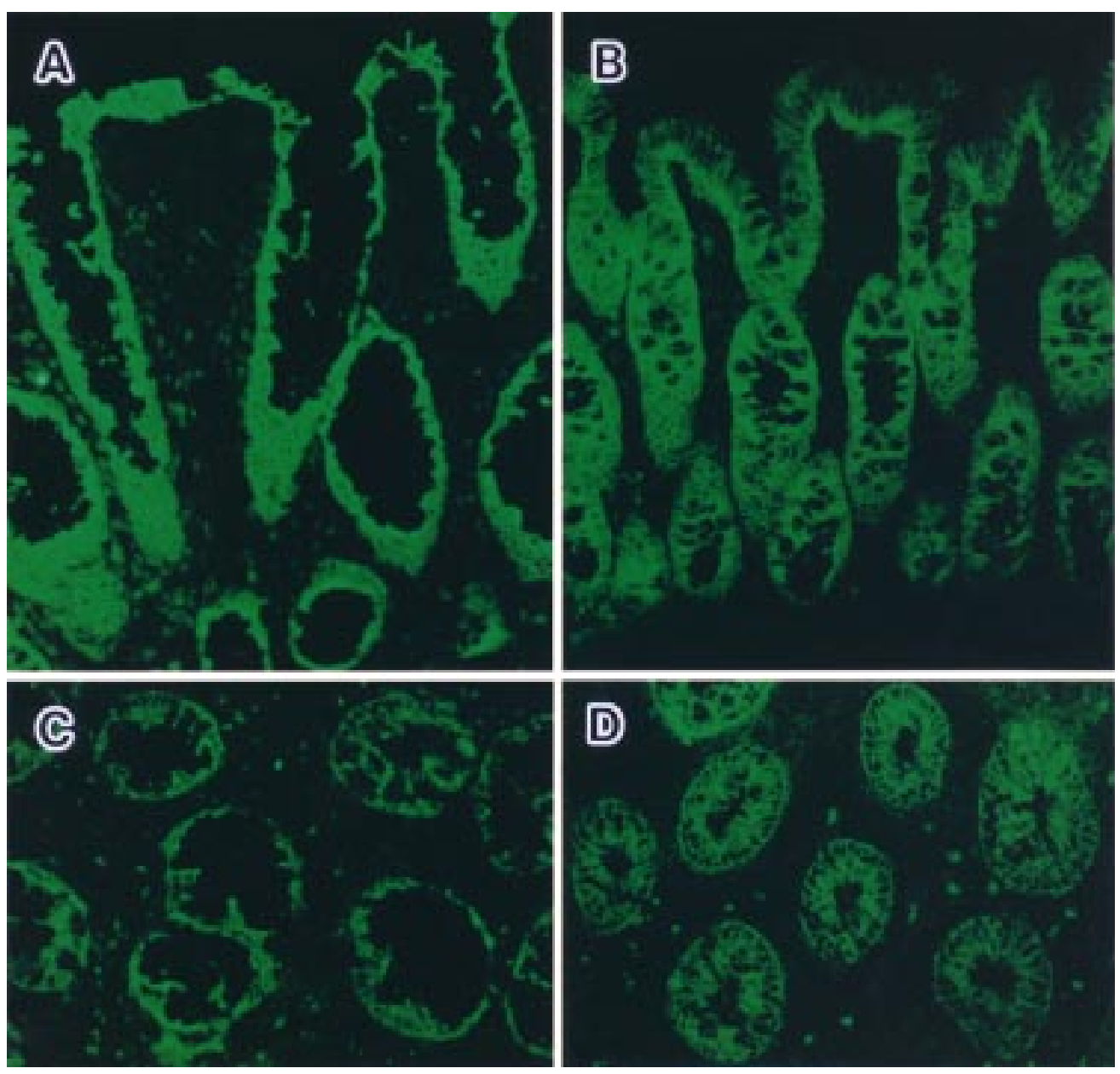

Figure 6 Immunohistochemical detection of Fas in colonic mucosa. Sections from active ulcerative colitis lesions $(A, C)$ and normal colon $(B, D)$ were stained with mouse monoclonal antibody against human Fas. Original magnification: $\times$ 129.

PREPARATION OF LAMINA PROPRIA LYMPHOCYTES (LPLS)

Mucosal specimens were obtained surgically from patients with ulcerative colitis or Crohn's disease for the preparation of LPLs. Resected colon specimens from patients with colon cancer, which were confirmed by microscopy to be free from cancer cells, were used for the preparation of normal control LPLs. LPLs were isolated from mucosal specimens as previously described. ${ }^{26}$ In brief, mucosal specimens were first washed with Hanks balanced salt solution without calcium or magnesium (HBSS), and then with HBSS containing 1 $\mathrm{mM}$ dithiothreitol (Sigma Chemical, St Louis, Missouri, USA) and antibiotics. To remove epithelial cells, the specimens were incubated three times in HBSS containing $0.5 \mathrm{mM}$ EDTA for 20 minutes at $20^{\circ} \mathrm{C}$. After three washes, the mucosal specimens were diced, and digested with $25 \mathrm{U} / \mathrm{ml}$ collagenase (Worthington, Freehold, New Jersey, USA) in HBSS containing $5 \%$ fetal calf serum, $10 \mathrm{mM}$ Hepes, and antibiotics for three or four hours at $37^{\circ} \mathrm{C}$ in a humid atmosphere of $5 \% \mathrm{CO}_{2}$ and $95 \% \mathrm{O}_{2}$. After filtration to remove debris, cells in the medium were washed twice with HBSS, resuspended in HBSS containing 5\% fetal calf serum, and layered on Ficoll-Paque solution (Pharmacia Biotech, Uppsala, Swe- den) to isolate LPLs by a density gradient method. Cell viability of the resulting mononuclear cells consistently exceeded $95 \%$, as confirmed by trypan blue exclusion.

FLOW CYTOMETRY

Isolated LPLs were washed twice in PBS containing $2 \%$ fetal calf serum and preincubated on ice for 15 minutes with hamster IgG to prevent non-specific binding of antibodies. The cells were then incubated on ice for 30 minutes with hamster anti-human FasL antibody $^{27}$ or control hamster IgG (Pharmingen, San Diego, California, USA). After a wash with PBS, cells were stained with secondary fluorescein isothiocyanate conjugated mouse anti-hamster IgG for 30 minutes on ice. The cells were then washed, preincubated on ice for 15 minutes with mouse IgG, and treated with phycoerythrin conjugated mouse anti-human CD3 antibody (Dako, Glostrup, Denmark) or phycoerythrin conjugated control mouse IgG (Becton Dickinson, San Jose, California, USA). After three washes with PBS, the stained cells were analysed on a flow cytometer (FACS Calliber; Becton Dickinson). CD3 lymphocytes were gated on a histogram and the expression of FasL on CD3 cells was analysed using CellQuest software (Becton Dickinson). 


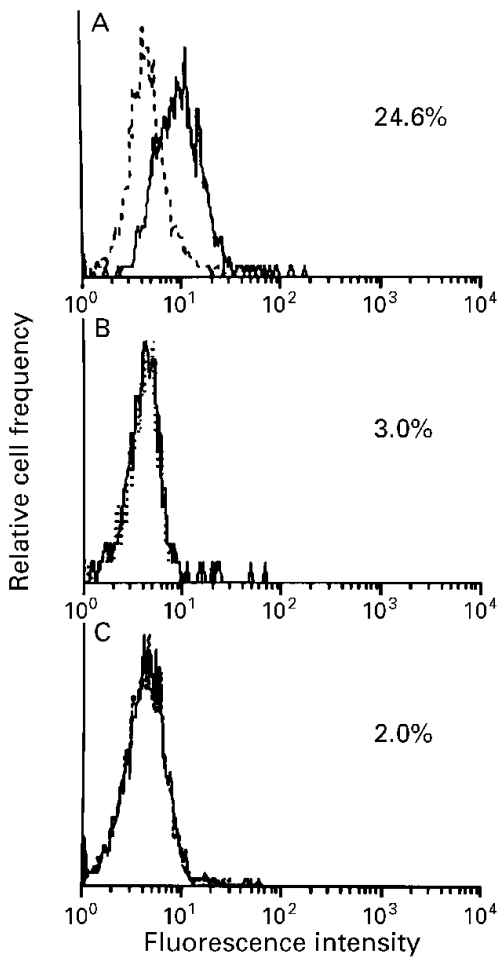

D

Figure 7 Flow cytometric analysis of Fas ligand (FasL) expression on CD3 lamina propria lymphocytes (LPLs). Expression of FasL on CD3 LPLs isolated from (A) involved colonic lesions of ulcerative colitis, $(B)$ active lesions of Crohn's disease, and $(C)$ control colon mucosa was examined by immunofluorescence and FACS analysis. LPLs were stained with anti-human FasL antibody (solid line) or an isotype-matched control antibody (dotted line). Representative data from five or six cases each are shown. (D) Percentage of FasL expressing cells in CD3 LPLs.

Results

INCREASE IN FasL TRANSCRIPTS IN ACTIVE

LESIONS OF PATIENTS WITH ULCERATIVE COLITIS EXCEPT FOR PROCTITIS-TYPE ULCERATIVE COLITIS To quantify FasL transcripts, we examined the correlation between the amount of FasL PCR products and the amount of RNA in the sample. PCR was performed for the FasL transcript in a mixture of colon derived RNAs (0, $80,160,320$, and $640 \mathrm{ng}$ ) and $4 \mathrm{ng}$ CTLL-2 RNA. For peak:height ratios ranging from 0 to 0.6 , a linear correlation was observed between the peak:height ratio of normalised FasL PCR products and the amount of RNA present (data not shown). All values for FasL PCR products were within $11 \%$ of the mean using this method. Accordingly, the amounts of FasL PCR transcripts were quantified within this range, and we employed this PCR method for quantification of FasL transcript in the following investigations. The amounts of FasL transcripts were determined in active ulcerative colitis lesions, inactive ulcerative colitis lesions, and Crohn's disease lesions, and compared with the amounts in normal colon mucosa. A significant increase in FasL transcripts (0.074 (0.057)) was observed in active ulcerative colitis lesions compared with inactive ulcerative colitis mucosal lesions (0.014 (0.009), $\mathrm{p}<0.005)$, active Crohn's disease lesions $(0.028$ (0.011), $\mathrm{p}<0.005)$, and normal controls $(0.020$ $(0.011), \mathrm{p}<0.005)$ (means (SD)) (fig 2). In patients with inactive ulcerative colitis or active Crohn's disease, FasL transcripts were essentially present at the same level as those in normal controls. We next divided the subjects with active ulcerative colitis into three subgroups, based on the distribution of ulcerative colitis involved sites in the colon (those with total colitis, left sided colitis, and proctitis-type colitis), and analysed FasL transcript level. All biopsy specimens were taken from the rectum. On histological examination, no significant differences in the severity of inflammation of the ulcerative colitis mucosal lesions analysed were evident between total colitis, left sided colitis, and proctitis-type colitis, based on Matts' grading system. As shown in fig 3, levels of FasL transcripts in rectal mucosal lesions were high for total colitis and left sided colitis, but for proctitis-type ulcerative colitis they were not increased beyond those of inactive subjects. Overall, the results show that FasL transcripts were increased in active lesions of the patients with ulcerative colitis except for those with proctitis-type ulcerative colitis, but not in those with active Crohn's disease.

INCREASE IN FasL TRANSCRIPTS AT THE SITE OF INFLAMMATION

To evaluate whether the increase in FasL transcripts occurred only in the affected mucosa, the amounts of FasL transcript were examined in both the involved and uninvolved colonic mucosa in the same patient with left sided colitis. As shown in fig 4, the levels of FasL transcripts in the involved lesions were 1.7 to 5.6 (3.7 (1.5)) times higher than for the uninvolved mucosa. The FasL transcript levels in normal colon mucosa were independent of the biopsy site (data not shown). Consequently, the level of FasL transcripts reflects the degree of inflammation focally present. 
HIGH EXPRESSION OF FasL mRNA IN MONONUCLEAR CELLS INFILTRATING MUCOSAL LESIONS OF ACTIVE ULCERATIVE COLITIS

FasL mRNA was localised by ISH in active ulcerative colitis lesions. FasL mRNA signals were detected on the infiltrating mononuclear inflammatory cells (fig 5A and $\mathrm{B}$ ). No significant signals were detected in epithelial cells or other interstitial cells. In specimens from four healthy individuals and four patients with Crohn's disease, the infiltrating cells showed little or no staining (fig 5C and D). Hybridisation was also performed with a sense probe, and no signals were detected (data not shown). Thus the increase in the amount of FasL transcript, as detected by quantitative RT-PCR, was due to the high expression of FasL on mononuclear cells infiltrating the ulcerative colitis lesions.

CONSERVATIVE EXPRESSION OF FAS ON COLON EPITHELIA FROM BOTH NORMAL SUBJECTS AND PATIENTS WITH ULCERATIVE COLITIS

To analyse the pathogenic role of FasL expressing cells in ulcerative colitis lesions, we investigated the expression of Fas on epithelial cells in ulcerative colitis. Fas expression was examined immunohistochemically using an antibody against Fas. As shown in fig 6, Fas was diffusely expressed on colon epithelia from both normal subjects and patients with ulcerative colitis. Weak immunoreactivity was detected on the infiltrating inflammatory cells. In colon specimens from patients with Crohn's disease or inactive ulcerative colitis, Fas was conservatively expressed on epithelia (data not shown).

EXPRESSION OF FasL IN CD3 LPLS INFILTRATING INVOLVED ULCERATIVE COLITIS LESIONS

Flow cytometric analysis was performed to determine the phenotype of LPLs expressing FasL. As shown by analysis of LPLs by two colour immunofluorescence cytometry (fig 7), FasL positive cells were detected in CD3 LPLs from active ulcerative colitis lesions. FasL expressing CD3 LPLs constituted 16.9 (8.9)\% of the total population in six patients with active ulcerative colitis, but only $1.3(0.9)$ and $2.9(1.7) \%$ in five normal subjects and five patients with active Crohn's disease respectively. In addition, more than $95 \%$ of LPLs were determined to be CD3 positive in active ulcerative colitis colon specimens (data not shown). Collectively, the results of ISH and flow cytometric analysis indicate that FasL is highly and specifically expressed on CD3 lymphocytes infiltrating the active ulcerative colitis lesions. In contrast, FasL expression was not increased in LPLs from active Crohn's disease lesions or normal colon tissue.

\section{Discussion}

In ulcerative colitis, chronic inflammation is restricted to the colonic mucosa, where colonic epithelial cell injury is commonly observed in active lesions. One form of epithelial injury is reported to involve apoptosis. In active ulcerative colitis lesions, the proportion of apoptotic cells is increased in colonic epithelia. ${ }^{28}$ Data herein indicate that Fas is conservatively expressed on the epithelia of both normal colon and that with ulcerative colitis lesions. Fas mediated apoptosis probably participates in the epithelial cell injury in ulcerative colitis. This study shows that FasL transcripts are highly expressed only in affected mucosa in patients with active ulcerative colitis, and that FasL mRNA is strongly expressed in $\mathrm{T}$ lymphocytes infiltrating the lamina propria of affected mucosa. These findings suggest that the binding of FasL expressed on $\mathrm{T}$ lymphocytes induces apoptosis in colon epithelia that express Fas, resulting in the severe colonic inflammation seen in patients with ulcerative colitis. In Crohn's disease, another chronic inflammatory bowel disease, no FasL transcripts were detected in active lesions, suggesting that FasL is not involved in the inflammation observed in Crohn's disease. Unlike the limited involvement of the upper mucosal layer in the colon in ulcerative colitis, the inflammatory lesion in Crohn's disease extensively involves the digestive tract transmurally. In addition, Crohn's disease lesions are not limited to the colon, but skip segmentally to include the ileum, jejunum, duodenum, and even the stomach, in contrast with the colon-limited mucosal lesions in patients with ulcerative colitis. In active Crohn's disease lesions, macrophages, but not CTLs, have been critically implicated in the onset and progression of Crohn's disease. ${ }^{29-31}$ These findings and our results indicate that the pathogenesis of ulcerative colitis is different from that of Crohn's disease. Our results may reflect the insignificance of CTL induced apoptosis in Crohn's disease, thereby resulting in the different clinical features of these two inflammatory bowel diseases. Of the several types of ulcerative colitis known, the proctitis type has unique features, with involvement limited to the rectum, a milder clinical course, and a better prognosis than other types. These unique manifestations suggest that the pathogenesis of proctitis-type ulcerative colitis may differ from that of other types of ulcerative colitis. This study shows that FasL transcripts were not increased in active lesions of proctitis-type ulcerative colitis, in contrast with the high levels in the other two types. Thus Fas-FasL mediated apoptosis is not involved in the pathogenesis of proctitis-type ulcerative colitis, which is also one of the unique manifestations of this type. In the gastrointestinal tract, expression of FasL is reported to be limited to a small proportion of the lamina propria cells ${ }^{32}$ and Paneth cells in normal mucosa. ${ }^{33}$ In mucosal lesions of patients with ulcerative colitis, highly elevated levels of FasL transcripts have been detected in metaplastic Paneth cells and FasL expressing inflammatory cells. ${ }^{33}$ Our study shows that, in mucosal lesions of patients with ulcerative colitis, FasL transcripts are greatly increased in infiltrating inflammatory cells. The results also indicate that FasL mRNA positive cells infiltrating ulcerative colitis lesions are largely CD3 T lymphocytes. Thus the CD3 $\mathrm{T}$ lymphocytes with surface FasL may be involved, at least in part, in the 
pathogenesis of ulcerative colitis. Previous reports indicate that the cross-linking of Fas by anti-Fas stimulated the production of interleukin 8 in colon epithelium derived HT-29 cells. ${ }^{34}$ Interleukin 8 has been found to potently induce the migration of neutrophils and lymphocytes. ${ }^{35-37}$ The high expression of FasL in ulcerative colitis may induce interleukin 8 production and secretion from colonic epithelia, promoting the migration and activation of lymphocytes and neutrophils. As a result, the increase in FasL on CD3 $\mathrm{T}$ lymphocytes in active ulcerative colitis is thought to play a role in the chronic inflammation of ulcerative colitis by the following two mechanisms: directly through the induction of apoptosis in Fas expressing colon epithelia, as discussed above, and indirectly through interleukin 8 induction, enhancing migration and activation of neutrophils and lymphocytes, resulting in the progression of mucosal lesion in ulcerative colitis. Collectively, our results indicate that FasL is increased on CD3 $\mathrm{T}$ lymphocytes in active ulcerative colitis, leading to the progression of mucosal lesions in all types of ulcerative colitis except the proctitis type. Disruption of the Fas-FasL system is probably involved, in part, in the pathogenesis of ulcerative colitis, at least in active-type ulcerative colitis. Further investigation with a view to therapy for ulcerative colitis will be necessary to determine the ulcerative colitis specific factors that enhance the Fas-FasL system.

The authors thank Drs M Yoshimura, H Yoshida, and M Ogawa for suggestions on cytometric analysis, and Dr N Itoh for advice for suggestions on cytometric analysis,
on immunohistochemical procedures.

1 Das KM, Dubin R, Nagai T. Isolation and characterization of colonic tissue-bound antibodies from patients with idiopathic ulcerative colitis. Proc Natl Acad Sci USA 1978;75:4528-32

2 Targan S, Saxon A, Landers C, et al. Serum anti-neutrophil cytoplasmic antibodies distinguish ulcerative colitis from Crohn's disease patients [abstract]. Gastroenterology 1989, 109:96A505.

3 Sadlack B, Merz H, Schorle H, et al. Ulcerative colitis-like disease in mice with a disrupted interleukin-2 gene. Cell 1993;75:253-61

4 Kühn R, Löhler J, Rennick D, et al. Interleukin-10-deficient mice develop chronic enterocolitis. Cell 1993;75:263-74.

5 Mombaerts E, Mizoguchi E, Grusby MJ, et al. Spontaneous development of inflammatory bowel disease in $\mathrm{T}$ cell receptor mutant mice. Cell 1993;75:275-82.

6 Nagata S, Golstein P. The Fas death factor. Science 1995;267:1449-56.

7 Smith CA, Farrah T, Goodwin RG. The TNF receptor superfamily of cellular and viral proteins: activation, superfamily of cellular and viral proteins:

8 Suda T, Takahashi T, Golstein P, et al. Molecular cloning and expression of the Fas ligand: a novel member of the and expression of the Fas ligand: a novel member

9 Gruss HJ, Dower S. Tumor necrosis factor ligand superfamily: involvement in the pathology of malignant superfamily: involvement in the patho

10 Mogil RJ, Radvanyi L, Gonzalez-Quintial R, et al. Fas (CD95) participates in peripheral $\mathrm{T}$ cell deletion and associated apoptosis in vivo. Int Immunol 1995;7:1451-8.

11 Watanabe-Fukunaga R, Brannan CI, Copeland NG, et al. Lymphoproliferation disorder in mice explained by defects in Fas antigen that mediates apoptosis. Nature 1992;356: 314-17.
12 Takahashi T, Tanaka M, Brannan CI, et al. Generalized lymphoproliferative disease in mice, caused by a point lymphoproliferative disease in mice, caused by
mutation in the Fas ligand. Cell 1994;76:969-76.

13 Rieux-Laucat F, Le Deist F, Hivroz C, et al. Mutations in Fas associated with human lymphoproliferative syndrome and autoimmunity. Science 1996;268:1347-9.

14 Fisher GH, Rosenberg FJ, Straus SE, et al. Dominant interfering Fas gene mutations impair apoptosis in a human autoimmune lymphoproliferative syndrome. Cell 1995;81: 935-46.

15 Ogasawara J, Watanabe-Fukunaga R, Adachi M, et al. Lethal effect of the anti-Fas antibody in mice. Nature 1993;364: 806-9.

16 Galle PR, Hoffmann WJ, Walczak $\mathrm{H}$, et al. Involvement of the CD95 (APO-1/Fas) receptor and ligand in liver the CD95 (APO-1/Fas) receptor and

17 Suda T, Okazaki T, Naito Y, et al. Expression of the Fas ligand in cells of T cell lineage. F Immunol 1995;154:3806-13.

18 Hanabuchi S, Koyanagi M, Kawasaki A, et al. Fas and its ligand in a general mechanism of T-cell-mediated cytotoxicity. Proc Natl Acad Sci USA 1994;91:4930-4.

19 Leithäuser F, Dhein J, Mechtersheimer G, et al. Constitutive and induced expression of Apo-I, a new member of the nerve growth factor/tumor necrosis factor receptor superfamily, in normal and neoplastic cells. Lab Invest 1993;69: 415-29.

20 Kondo S, Imamura I, Shinomura Y, et al. Determination of histidine decarboxylase mRNA in various rat tissues by the polymerase chain reaction. Inflamm Res 1995;44:111-15.

21 Kondo S, Shinomura Y, Kanayama S, et al. Helicobacter pylori increases gene expression of hepatocyte growth factor in human gastric mucosa. Biochem Biophys Res Commun 1995;210:960-5.

22 Matts F. The value of rectal biopsy in the diagnosis of ulcerative colitis. QfM 1961;120:393-407.

23 Chomczynski P, Sacchi N. Single-step method of RNA isolation by acid guanidinium thiocyanate-phenol-chloroform extraction. Anal Biochem 1987;162:156-9.

24 Takahashi T, Tanaka M, Inazawa J, et al. Human Fas ligand: gene structure, chromosomal location and species specificity. Int Immunol 1994;6:1567-74.

25 Hirota S, Itoh A, Morii E, et al. Localization of mRNA for c-kit receptor and its ligand in the brain of adult rats: an analysis using in situ hybridization histochemistry. Molecular Brain Research 1992;15:47-54.

26 Fais S, Capobianchi MR, Pallone F, et al. Spontaneous release of interferon $\gamma$ by intestinal lamina propria lymphocytes in Crohn's disease. Kinetics of in vit

27 Tanaka M, Suda T, Haze K, et al. Fas ligand in human serum Nat Med 1996;2:317-22.

28 Lee FD. Importance of apoptosis in the histopathology of drug related lesions in the large intestine. $\mathcal{F}$ Clin Pathol 1993; 46:118-22.

29 Murch SH, Braegger CP, Sessa WC. High endothelin-I immunoreactivity in Crohn's disease and ulcerative colitis. Lancet 1992;339:381-5.

30 Watanabe M, Tsuru S, Zinnaka Y, et al. Demonstration and characterization of immunosupressive factors in sera from patients with Crohn's disease. F Clin Lab Immunol 1985;17: 13-19.

31 Allison MC, Cornwall S, Poulter LW, et al. Macrophage heterogeneity in normal colonic mucosa and in inflammatory bowel disease. Gut 1988;29:1531-8.

32 De Maria R, Boirivant M, Cifone MG, et al. Functional expression of Fas and Fas ligand on human gut lamina propria T lymphocytes. A potential role for the acidic sphingo-
myelinase pathway in normal immunoregulation. $f$ Clin myelinase pathway in

33 Möller P, Walczak H, Riedl S, et al. Paneth cells express high levels of CD95 ligand transcripts. A unique property among gastrointestinal epithelia. Am F Pathol 1996;149:913.

34 Abreu-Martin MT, Vidrich A, Lynch DH, et al. Divergent induction of apoptosis and IL-8 secretion on HT-29 cells in response to TNF-alpha and ligation of Fas antigen. $f$ Immunol 1995;155:4147-54.

35 Larsen CG, Anderson AO, Appella E, et al. The neutrophilactivating protein (NAP-1) is also chemotactic for lymactivating protein (NAP-1) is also
phocytes. Science $1989 ; 243: 1464-6$.

36 Tanaka S, Robinson EA, Yoshimura T, et al. Synthesis and biological characterization of monocyte-derived neutrophil chemotactic factor. FEBS Lett 1988;236:467-70.

37 Lindley I, Aschauer H, Seifert JM. Synthesis and expression in Escherichia coli of the gene encoding monocyte-derived neutrophil-activating factor: biological equivalence between natural and recombinant neutrophil-activating factor. Proc Natl Acad Sci USA 1988;85:9199-203. 